\title{
Kemandirian Belajar Matematik Siswa SMP Melalui Pendekatan Hands-On Activity
}

\author{
Iin Ariyanti, ${ }^{1,}$ \\ ${ }^{1}$ Pendidikan Matematika, FKIP, Universitas Muhammadiyah Banjarmasin, \\ Jl. Gubernur Syarkawi, Lingkar utara, Barito Kuala, Kalimantan Selatan \\ e-mail: aiin.ariyanti1105@gmail.com
}

\begin{abstract}
The purpose of this study was to measure the self regulated learning of students who obtained mathematics learning using the Hands-On Activity approach compared to students who obtained conventional learning. The instrument used in this study was in the form of student mathematics self regulated learning questionnaire that consists of 23 statements (13 positive statements and 10 negative statements) with responses based on a Likert scale (score minimum 1 to score maximum 4). The results obtained in this study were the self regulated learning of students who obtained learning using the Hands-On Activity approach no more significantly higher compared to students who obtain conventional learning. However, if this Hands-On Activity is consistently applied in learning then it is not impossible that indicators of self regulated will appear in student's attitudes.
\end{abstract}

Keywords: mathematics self regulated learning, Hands-On Activity approach, junior high school students

\begin{abstract}
Abstrak
Tujuan penelitian ini adalah untuk mengukur kemandirian belajar siswa yang memperoleh pembelajaran matematika dengan menggunakan pendekatan Hands-On Activity dibandingkan dengan siswa yang memperoleh pembelajaran konvensional. Instrumen berupa angket kemandirian belajar matematik siswa yang terdiri dari 23 pernyataan (13 pernyataan positif dan 10 pernyataan negatif) dengan respon berdasarkan skala likert skor 1 sampai 4. Hasil yang diperoleh yaitu kemandirian belajar siswa yang memperoleh pembelajaran dengan menggunakan pendekatan Hands-On Activity tidak lebih tinggi secara signifikan dibandingkan dengan siswa yang memperoleh pembelajaran konvensional. Akan tetapi, meskipun pencapaian kemandirian belajar siswa yang memperoleh pembelajaran dengan menggunakan pendekatan Hands-On Activity tidak lebih tinggi dari siswa yang memperoleh pembelajaran konvensional, jika Hands-On Activity ini secara konsisten diterapkan dalam pembelajaran maka bukan tidak mungkin akan memunculkan indikator kemandirian belajar dalam sikap siswa.
\end{abstract}

Kata kunci: Kemandirian belajar matematik, Pendekatan Hands-On Activity, Siswa SMP 


\section{PENDAHULUAN}

Dalam pembelajaran matematika, kemampuan afektif siswa juga tidak kalah pentingnya untuk diperhatikan dalam pencapaian pembelajaran. Kemampuan afektif yang berperan penting dalam menunjang kemampuan kognitif siswa adalah kemandirian belajar (Self Regulated Learning). Schunk dan Zimmerman [1], mendefinisikan kemandirian belajar sebagai suatu proses dimana siswa mengaktifkan dan mendukung pengetahuan, tingkah laku, dan perasaan yang secara sistematis berorientasi pada tujuan yang ingin dicapai oleh siswa. Menurut Darr dan Fisher [2], siswa diharapkan untuk mengembangkan kemampuan kemandirian belajar agar siswa dapat berinteraksi dengan ide-ide matematis dengan suatu cara yang aktif dan konstruktif dimana kemampuan kemandirian berkorelasi tinggi dengan kesuksesan siswa dalam belajar. Hal ini mengindikasikan bahwa kemandirian belajar berpengaruh positif terhadap kemampuan kognitif siswa. Selain itu, Turmudi [3], menambahkan siswa akan belajar lebih baik ketika siswa tersebut memenuhi indikator kemandirian belajar yaitu dapat mengontrol belajar sendiri dengan membuat tujuan dan memonitor kemajuan mereka sendiri serta menjadikan siswa pribadi yang percaya diri pada kemampuannya dalam menyelesaikan permasalahan yang sulit, berani melukiskan sesuatu sendiri, fleksibel dalam mengeksplorasi gagasan matematika dan mencoba mencari alternatif pola penyelesaian, serta berkemauan untuk bekerja secara tekun. Dapat disimpulkan bahwa kemandirian belajar sangat penting sehingga perlu ditumbuhkan dalam proses belajar mengajar.

Dalam menciptakan kemandirian belajar dalam proses pembelajaran matematika, guru dapat menciptakan situasi yang melibatkan siswa secara aktif dalam membangun gagasannya sendiri. Guru dapat menggunakan pendekatan/strategi/model yang dapat merangsang siswa untuk menanamkan sikap sikap yang terdapat dalam indikator kemandirian belajar. Guru dapat menggunakan 


\section{Hipotenusa}

Journal of Research Mathematics Education

pendekatan Hands-On Activity. Pendekatan Hands-On Activity menurut Kartono [4], adalah suatu kegiatan yang dirancang untuk melibatkan siswa dalam menggali informasi dan bertanya, beraktivitas dan menemukan, mengumpulkan data dan menganalisis serta membuat kesimpulan sendiri dimana melalui pembelajaran ini siswa diberikan kebebasan dalam mengkonstruk pemikiran dan temuan selama melakukan aktivitas sehingga siswa melakukan sendiri dengan tanpa beban, menyenangkan, dan dengan motivasi yang tinggi. Pembelajaran dengan pendekatan Hands-On Activity memberikan pengalaman dan penghayatan bagi siswa dalam memahami konsep-konsep yang dipelajari serta mendorong ingin tahu siswa secara lebih mendalam sehingga cenderung untuk membangkitkan siswa mengadakan penelitian untuk mendapatkan pengamatan dan pengalaman dalam proses ilmiah [4].

Adapun indikator kemandirian belajar yang digunakan dalam penelitian ini berdasarkan indikator yang telah dirangkum oleh Hendriana \& Sumarmo [5], diantaranya: (1) inisiatif dan motivasi belajar intrinsik, (2) kebiasaan mendiagnosa kebutuhan belajar sendiri, (3) menetapkan tujuan/ target belajar, (4) memonitor, mengatur, dan mengontrol belajar, (5) memandang kesulitan sebagai tantangan, (6) memanfaatkan dan mencari sumber bahan belajar yang relevan, (7) memilih, dan menerapkan strategi belajar, (8) mengevaluasi proses dan hasil belajar, dan (9) self efficacy atau konsep diri.

\section{METODE PENELITIAN}

Tujuan penelitian ini adalah untuk mengukur kemandirian belajar siswa yang memperoleh pembelajaran matematika dengan menggunakan pendekatan Hands-On Activity dibandingkan dengan siswa yang memperoleh pembelajaran konvensional. Lokasi penelitian di salah satu SMPN di Banjarmasin. Sampel yang diambil adalah kelas 
VII sebanyak 2 kelas dari populasi seluruh siswa kelas VII sebanyak 250 siswa. Tekhnik yang digunakan dalam menentukan sampling penelitian ini adalah teknik purposive sampling yaitu suatu teknik yang digunakan dalam pengambilan subjek dengan didasarkan atas adanya tujuan tertentu [6],. Adapun yang menjadi kelas eksperimen adalah kelas VIIB sedangkan kelas kontrol adalah kelas VIIA dengan jumlah siswa yang sama baik kelas eksperimen maupun kelas kontrol yaitu sebanyak 36 siswa. Akan tetapi, total sampel yang terlibat dalam penelitian ini sebanyak 67 orang dikarenakan pada saat awal pertemuan 3 orang tidak hadir di kelas eksperimen dan 2 orang tidak hadir di kelas kontrol. Materi yang diajarkan pada kedua kelas baik kelas eksperimen maupun kelas kontrol pada saat pembelajaran mengunakan hands-on acivity adalah materi segiempat.

Instrumen kemandirian belajar matematik siswa berupa angket. Angket kemandirian belajar matematik siswa terdiri dari 23 pernyataan (13 pernyataan positif dan 10 pernyataan negatif). Respon kesetujuan siswa terdiri dari 4 alternatif pilihan berdasarkan skala likert yang telah dimodifikasi dengan menghilangkan pilihan raguragu (R). Tujuannya adalah agar siswa dapat memilih respon dengan pasti terhadap pernyataan yag diberikan. Pemberian skor terhadap pernyataan positif yaitu skor 1 untuk pilihan sangat tidak setuju (STS), skor 2 untuk pilihan tidak setuju (TS), skor 3 untuk pilihan setuju (S), dan skor 4 untuk pilihan sangat setuju (SS) sedangkan untuk pernyatan negatif berlaku pemberian skor sebaliknya. Instrumen telah divalidasi secara teoretik maupun empirik. Instrumen angket kemandirian belajar matematik siswa diberikan di akhir pembelajaran baik pada siswa kelas eksperimen maupun kelas kontrol. 


\section{HASIL DAN PEMBAHASAN}

Data kemandirian belajar siswa diperoleh dengan mengumpulkan hasil angket kemandirian belajar siswa. Angket diberikan setelah siswa mendapatkan perlakuan atau di akhir pembelajaran baik pada siswa kelas eksperimen maupun pada siswa kelas kontrol. Adapun angket ini dikumpulkan dengan tujuan untuk menguji "kemandirian belajar siswa yang memperoleh pembelajaran dengan menggunakan HandsOn Activity lebih tinggi dibandingkan dengan siswa yang memperoleh pembelajaran konvensional". Hasil distribusi jawaban data kemandirian belajar siswa baik kelas eksperimen maupun kontrol dapat dilihat pada tabel berikut.

Tabel 1. Distribusi Jawaban Data Kemandirian Belajar Siswa Kelas Eksperimen

\begin{tabular}{|c|c|c|c|c|c|c|c|c|c|c|}
\hline \multirow{3}{*}{ Indikator } & \multirow{2}{*}{\multicolumn{2}{|c|}{ Pernyataan }} & \multicolumn{8}{|c|}{ Jawaban } \\
\hline & & & \multicolumn{2}{|c|}{ SS } & \multicolumn{2}{|c|}{$\mathbf{S}$} & \multicolumn{2}{|c|}{ TS } & \multicolumn{2}{|c|}{ STS } \\
\hline & No & $+/-$ & $\mathrm{F}$ & $\%$ & $\mathrm{~F}$ & $\%$ & $\mathrm{f}$ & $\%$ & $\mathrm{f}$ & $\%$ \\
\hline Inisiatif Belajar & 1 & + & 28 & 84,8 & 4 & 12,1 & 1 & 3 & 0 & 0 \\
\hline dan Motivasi & 2 & - & 0 & 0 & 4 & 12,1 & 17 & 51,5 & 12 & 36,4 \\
\hline Belajar Intrinsik & 3 & + & 15 & 45,5 & 14 & 51,5 & 4 & 3 & 0 & 0 \\
\hline Mendiagnosis & 5 & + & 15 & 45,5 & 17 & 51,5 & 1 & 3 & 0 & 0 \\
\hline $\begin{array}{l}\text { Kebutuhan } \\
\text { Belajar }\end{array}$ & 6 & - & 3 & 9,1 & 4 & 12,1 & 14 & 42,4 & 12 & 36,4 \\
\hline Mene & 7 & + & 19 & 57,6 & 13 & 39,4 & 1 & 3 & 0 & 0 \\
\hline Tuene & 8 & + & 12 & 36,4 & 16 & 48,5 & 4 & 12,1 & 1 & 3 \\
\hline I ujuan Belajar & 9 & - & 2 & 6,1 & 0 & 0 & 15 & 48,5 & 16 & 36,4 \\
\hline Mengatur dan & 10 & + & 13 & 39,4 & 19 & 57,6 & 0 & 0 & 1 & 3,1 \\
\hline Mengontrol & 11 & - & 0 & 0 & 8 & 24,2 & 20 & 60,6 & 5 & 15,2 \\
\hline Kinerja/Belajar & 12 & + & 19 & 27,6 & 14 & 42,4 & 0 & 0 & 0 & 0 \\
\hline $\begin{array}{l}\text { Memandang } \\
\text { Kesulitan }\end{array}$ & 13 & + & 12 & 36,4 & 20 & 42,4 & 1 & 27,3 & 0 & 0 \\
\hline $\begin{array}{c}\text { sebagai } \\
\text { Tantangan }\end{array}$ & 14 & - & 0 & 0 & 9 & 27,3 & 14 & 42,4 & 10 & 30,3 \\
\hline $\begin{array}{l}\text { Mencari dan } \\
\text { Memanfaatkan }\end{array}$ & 15 & - & 2 & 6,1 & 4 & 12,1 & 24 & 72,7 & 3 & 9,1 \\
\hline $\begin{array}{c}\text { Sumber Belajar } \\
\text { yang Relevan }\end{array}$ & 16 & + & 19 & 57,6 & 14 & 42,4 & 0 & 0 & 0 & 0 \\
\hline Memilih dan & 17 & + & 9 & 27,3 & 14 & 42,4 & 9 & 27,3 & 1 & 3 \\
\hline Menerapkan & 18 & - & 2 & 6,1 & 8 & 24,2 & 19 & 57,6 & 4 & 12,1 \\
\hline Strategi Belajar & 19 & + & 10 & 30,3 & 22 & 66,7 & 1 & 3 & 0 & 0 \\
\hline
\end{tabular}




\begin{tabular}{|c|c|c|c|c|c|c|c|c|c|c|}
\hline \multirow{3}{*}{ Indikator } & \multirow{2}{*}{\multicolumn{2}{|c|}{ Pernyataan }} & \multicolumn{8}{|c|}{ Jawaban } \\
\hline & & & \multicolumn{2}{|c|}{ SS } & \multicolumn{2}{|c|}{$\mathbf{S}$} & \multicolumn{2}{|c|}{ TS } & \multicolumn{2}{|c|}{ STS } \\
\hline & No & $+/-$ & $\mathrm{F}$ & $\%$ & $\mathrm{~F}$ & $\%$ & $\mathrm{f}$ & $\%$ & $\mathrm{f}$ & $\%$ \\
\hline & 20 & - & 3 & 9,1 & 7 & 21,2 & 17 & 51,5 & 6 & 18,2 \\
\hline Mengevaluasi & 21 & + & 11 & 33,3 & 15 & 45,5 & 7 & 21,2 & 0 & 0 \\
\hline $\begin{array}{c}\text { Proses dan Hasil } \\
\text { Belajar }\end{array}$ & 22 & - & 4 & 12,1 & 7 & 21,2 & 17 & 51,5 & 5 & 15,2 \\
\hline Self Eficacy & 24 & + & 16 & 48,5 & 13 & 39,4 & 3 & 9,1 & 1 & 3 \\
\hline (Konsep diri) & 25 & - & 6 & 18,2 & 6 & 18,2 & 13 & 39,4 & 8 & 24,2 \\
\hline
\end{tabular}

Tabel 2. Distribusi Jawaban Data Kemandirian Belajar Siswa

Kelas Kontrol

\begin{tabular}{|c|c|c|c|c|c|c|c|c|c|c|}
\hline \multirow{3}{*}{ Indikator } & \multirow{2}{*}{\multicolumn{2}{|c|}{ Pernyataan }} & \multicolumn{8}{|c|}{ Jawaban } \\
\hline & & & \multicolumn{2}{|c|}{ SS } & \multicolumn{2}{|c|}{$\mathbf{S}$} & \multicolumn{2}{|c|}{ TS } & \multicolumn{2}{|c|}{ STS } \\
\hline & No & $+/-$ & $\mathrm{f}$ & $\%$ & $\mathrm{f}$ & $\%$ & $\mathrm{~F}$ & $\%$ & $\mathrm{f}$ & $\%$ \\
\hline Inisiatif Belajar & 1 & + & 27 & 79,4 & 7 & 20,6 & 0 & 0 & 0 & 0 \\
\hline dan Motivasi & 2 & - & 0 & 0 & 17 & 50 & 14 & 41,2 & 3 & 8,8 \\
\hline Belajar Intrinsik & 3 & + & 7 & 20,6 & 22 & 64,7 & 5 & 14,7 & 0 & 0 \\
\hline Mendiagnosis & 5 & + & 12 & 35,3 & 19 & 55,9 & 3 & 8,8 & 0 & 0 \\
\hline $\begin{array}{l}\text { Kebutuhan } \\
\text { Belajar }\end{array}$ & 6 & - & 2 & 5,9 & 8 & 23,5 & 21 & 61,7 & 3 & 8,8 \\
\hline Menetapkan & 7 & + & 17 & 50 & 13 & 38,2 & 4 & 11,8 & 0 & 0 \\
\hline Tuiuan Belaiar & 8 & + & 5 & 14,7 & 21 & 61,8 & 7 & 20,6 & 1 & 2,9 \\
\hline & 9 & - & 0 & 0 & 2 & 5,9 & 18 & 52,9 & 14 & 41,2 \\
\hline Mengatur dan & 10 & + & 15 & 44,1 & 17 & 50 & 2 & 5,9 & 0 & 0 \\
\hline Mengontrol & 11 & - & 1 & 2,9 & 16 & 47,1 & 13 & 38,2 & 4 & 11,8 \\
\hline Kinerja/Belajar & 12 & + & 14 & 41,2 & 17 & 50 & 3 & 8,8 & 0 & 0 \\
\hline Memandang & 13 & + & 15 & 44,1 & 14 & 41,2 & 5 & 14,7 & 0 & 0 \\
\hline $\begin{array}{c}\text { Kesulitan } \\
\text { sebagai } \\
\text { Tantangan }\end{array}$ & 14 & - & 0 & 0 & 10 & 29,4 & 19 & 55,9 & 5 & 14,7 \\
\hline $\begin{array}{c}\text { Mencari dan } \\
\text { Memanfaatkan }\end{array}$ & 15 & - & 1 & 2,9 & 9 & 26,5 & 16 & 47,1 & 8 & 23,5 \\
\hline $\begin{array}{l}\text { Sumber Belajar } \\
\text { yang Relevan }\end{array}$ & 16 & + & 14 & 41,2 & 16 & 47 & 4 & 11,8 & 0 & 0 \\
\hline Memilih dan & 17 & + & 8 & 23,5 & 17 & 50 & 9 & 26,5 & 0 & 0 \\
\hline Menerapkan & 18 & - & 0 & 0 & 9 & 26,5 & 20 & 58,8 & 5 & 14,7 \\
\hline Strategi Belajar & 19 & + & 12 & 35,3 & 20 & 58,8 & 2 & 5,9 & 0 & 0 \\
\hline & 20 & - & 1 & 2,9 & 12 & 35,3 & 13 & 38,2 & 8 & 23,5 \\
\hline $\begin{array}{l}\text { Mengevaluasi } \\
\text { Proses dan }\end{array}$ & 21 & + & 13 & 38,2 & 14 & 41,2 & 5 & 14,7 & 2 & 5,9 \\
\hline Hasil Belajar & 22 & - & 0 & 0 & 7 & 20,6 & 17 & 50 & 10 & 29,4 \\
\hline Self Eficacy & 24 & + & 15 & 44,1 & 13 & 38,2 & 6 & 17,6 & 0 & 0 \\
\hline (Konsep diri) & 25 & - & 4 & 11,7 & 21 & 61,8 & 9 & 26,5 & 0 & 0 \\
\hline
\end{tabular}




\section{Hipotenusa}

Journal of Research Mathematics Education

Selanjutnya dilakukan uji statistik terhadap data angket kemandirian belajar siswa. Namun, sebelum dilakukan uji statistik, data yang diperoleh diubah terlebih dahulu menggunakan method of successive interval (MSI). Tujuannya adalah untuk mengubah data kemandirian belajar siswa dari skala ordinal menjadi skala interval agar selanjutnya dapat dilakukan uji statistik dalam menguji hipotesis "kemandirian belajar siswa yang memperoleh pembelajaran dengan menggunakan Hands-On Activity lebih tinggi dibandingkan dengan siswa yang memperoleh pembelajaran konvensional". Setelah data kemandirian belajar diubah menjadi skor interval, selanjutnya dilakukan uji statistik berupa uji perbedaan dua kelompok saling bebas.

Berikut ini adalah rangkuman dari hasil uji normalitas terhadap data skor angket kemandirian belajar baik kelas eksperimen maupun kelas kontrol.

Tabel 3. Hasil Uji Normalitas Data Skor Angket Kemandirian Belajar

\begin{tabular}{|c|c|c|c|c|c|}
\hline \multirow{3}{*}{ Data } & \multicolumn{4}{|c|}{ Kemandirian Belajar } & \multirow{2}{*}{ Keputusan } \\
\cline { 2 - 6 } & Kelas & \multicolumn{3}{|c|}{ Shapiro-Wilk } \\
\cline { 2 - 6 } Angket & Stat & Df & Sig & \\
\cline { 2 - 6 } & $\begin{array}{c}\text { Eksperimen } \\
\text { Penatan Hands-On } \\
\text { Activity) }\end{array}$ & 0,974 & 33 & 0,597 & $\begin{array}{c}\text { H0 } \\
\text { diterima }\end{array}$ \\
\cline { 2 - 6 } & Konvensional & 0,965 & 34 & 0,333 & $\begin{array}{c}\text { H0 } \\
\text { diterima }\end{array}$ \\
\hline
\end{tabular}

Berdasarkan kriteria pengujian, maka baik kelas eksperimen maupun kelas kontrol memiliki nilai $\operatorname{sig}>\boldsymbol{\omega}=0,05$ sehingga H0 diterima. Dengan demikian, diperoleh kesimpulan bahwa data skor angket kemandirian belajar baik kelas eksperimen maupun kelas kontrol berdistribusi normal.

Setelah dilakukan uji normalitas, maka langkah selanjutnya dilakukan uji homogenitas terhadap hasil angket kemandirian belajar matematik siswa. Berikut ini adalah rangkuman dari hasil uji 


\section{Hipotenusa}

Journal of Research Mathematics Education

VOL. 3 NO.1 2020

homogenitas terhadap data skor angket kemandirian belajar antara kelas eksperimen dan kelas kontrol.

Tabel 4. Hasil Uji Homogenitas Data Skor Angket

Kemandirian Belajar

\begin{tabular}{ccccccc}
\hline \multicolumn{5}{c}{ Kemampuan Pemahaman Matematik } \\
Data & $\begin{array}{c}\text { Levene } \\
\text { Statistic }\end{array}$ & Df1 & Df2 & Sig & Keputusan \\
\hline $\begin{array}{c}\text { N-Gain } \\
\text { Ternormalisasi }\end{array}$ & 0,173 & 1 & 65 & 0,679 & Terima H0 \\
\hline
\end{tabular}

Berdasarkan kriteria pengujian, nilai sig $>u=0,05$ sehingga H0 diterima. Dengan kata lain, diperoleh kesimpulan bahwa kedua kelompok data angket kemandirian belajar bervariansi homogen. Oleh karena data berdistribusi normal dan juga homogeny, maka uji yang digunakan adalah uji perbedaan dua kelompok saling bebas menggunakan uji t. Berikut ini adalah rangkuman dari hasil uji perbedaan dua kelompok saling bebas terhadap data skor angket kemandirian belajar dengan menggunakan uji t.

Tabel 5. Hasil Uji Perbedaan Dua Kelompok Saling Bebas Data Skor Angket Kemandirian Belajar

\begin{tabular}{|c|c|c|c|c|}
\hline \multicolumn{5}{|c|}{ Kemampuan Pemahaman Matematik } \\
\hline \multirow[b]{2}{*}{ Data } & \multicolumn{3}{|c|}{ t-test for Equality of Means } & \multirow[b]{2}{*}{ Keputusan } \\
\hline & $\mathrm{T}$ & $\mathrm{df}$ & $\begin{array}{c}\text { Sig } \\
\text { (2tailed) }\end{array}$ & \\
\hline $\begin{array}{c}\text { N-gain } \\
\text { Ternormalisasi }\end{array}$ & 1,653 & 65 & 0,103 & Terima HO \\
\hline
\end{tabular}

Berdasarkan kriteria pengujian, sig(1 tailed) yaitu 0,0515 $>\alpha=$ 0,05 sehingga H0 diterima. Dengan demikian, diperoleh kesimpulan bahwa kemandirian belajar siswa yang memperoleh pembelajaran dengan menggunakan pendekatan Hands-On Activity tidak lebih tinggi secara signifikan dibandingkan dengan siswa yang memperoleh pembelajaran konvensional ditinjau secara keseluruhan. 


\section{KESIMPULAN DAN SARAN}

Berdasarkan hasil penelitian dan analisis data yang telah diperoleh , maka diperoleh kesimpulan bahwa kemandirian belajar siswa yang memperoleh pembelajaran dengan menggunakan pendekatan HandsOn Activity tidak lebih tinggi secara signifikan dibandingkan dengan siswa yang memperoleh pembelajaran konvensional. Akan tetapi, meskipun pencapaian kemandirian belajar siswa yang memperoleh pembelajaran dengan menggunakan pendekatan Hands-On Activity tidak lebih tinggi dari siswa yang memperoleh pembelajaran konvensional, jika Hands-On Activity ini secara konsisten diterapkan dalam pembelajaran maka bukan tidak mungkin akan memunculkan indikator kemandirian belajar dalam sikap siswa.

\section{DAFTAR PUSTAKA}

[1] Schunk, D.H. \& Zimmerman, B.J. (1994). Self-regulation in education: retrospect and prospect. In D.H Schunk \& B.J. Zimmerman (Eds.), Self-regulation of learning and performance. Hillsdale, NJ: Erlbaum

[2] Darr, C. \& Fisher, J. (2004). Self regulated learning in the mathematics class. Paper presented at NZARE Conference, Turning the Kaleidoscope, Wellington, 24 - 26 November 2004.

[3] Turmudi. (2009). Taktik dan strategi pembelajaran matematika: referensi untuk guru smp/mts, mahasiswa dan umum. Jakarta: Leuser Cita Pustaka.

[4] Kartono. (2010). Hands on activity pada pembelajaran geometri sekolah sebagai assesmen kinerja siswa. Jurnal Kreatif Inovatif, 1(1): 21-32.

[5] Hendriana, H. \& Soemarmo, U. (2014). Penilaian pembelajaran Matematika. Bandung : PT Refika Aditama.

[6] Arikunto, S. (2013). Prosedur penelitian: suatu pendekatan praktik. Jakarta: Rineka Cipta. 